Vol. 1, No 1, 2016

\title{
MACHINE LEARNING BASED DECISION SUPPORT FOR STUDENT ACADEMIC ADVISORY SYSTEM
}

\author{
S.C. $\mathrm{Ng}^{1 *}$, T.S. Lee ${ }^{1}$, B.P. Chew ${ }^{1}$ \\ ${ }^{1}$ School of Information Technology, SEGi University, Malaysia \\ *Email: ashleyng@segi.edu.my
}

\begin{abstract}
In the era towards human capital development, higher education institutions such as universities and colleges need to equip with the substantial capability of analysing student's academic achievement level for making appropriate academic decisions such as selecting a course specialisation. Choosing a suitable field of study significantly improves students' learning experience in their university studies. As a positive impact, this can help to reduce the drop-out rate of universities. However, most of the existing academic progression process to assign students to their specialisation is time consuming as each single process involves extensive analysis of data from different aspect of study. Personal consultancy may result in bias of advice which most of the time is based on the consultant's personal experience. This paper aims to propose a machine learning based decision support system for academic advisory. Artificial neural network (ANN) is applied as the decision support engine in the proposed model. This model assists academicians to make better decisions when assigning students to their specialisation. This study has taken a school of SEGi University to be the platform to run the preliminary testing on the proposed system. The third year students' academic records and their subjects' assessment in previous semesters were sampled as training set for the model. Experimental results showed that the proposed decision support model exhibits high accuracy in classifying students into two different specialisations according to their respective academic achievement levels.
\end{abstract}

Keywords: Artificial neural network (ANN), academic advisory system, machine learning

\section{I.0 INTRODUCTION}

Student's drop-out or attrition phenomenon has begun since long ago. Araque et al. (2009) have completed a thorough study on the factors influencing university drop-out rate reporting that the university drop-out rate in Spain has been set between 30\% and 50\%. Sangodiah et al. (2015) have reported that student retention rate is at the alerting state whereby the article also showed statistics on high students' drop-out rate at the tertiary level education in Malaysia and other countries. Student's attrition not only could possibly affect the students' future career, it also carries economic, social and psychological cost to the society (Alkan, 2014). Analysis by Araque et al. (2009) showed that the drop-out rate is inversely related to the academic performance rate, the success rate and the average mark. In order to reduce the drop-out rate, educational institutions have to improve or at least retain the students' academic performance. The effort should be initiated at the early stage when the students are choosing their course specialisation, which normally is done before admission or during year one (Abdykhalykova, 2013; Goga et al., 2015). Choosing the suitable course specialisation shall enhances the 
students' learning interest and leads them to better academic performance. In the process of choosing course specialisation, academic advisors in the institution play important roles as majority of the students are indecisive or need inputs to help them to decide what specialisation suits them most. It is inevitable that sometimes the academic advisor provides consultancy based on personal experience or self-presumption on certain specialisation. This might result in non-accurate or biased guidance provided to the students. This happens when the advisor is either not sure of the student's background or lack of subject knowledge. In order to understand the student's background, statistical analysis is needed. The statistics to be observed include student's academic and non-academic information such as students' preferences, previous academic performance and background. However, the analysis process is time consuming and bringing an immense managerial workload to not only the advisor as well as other staff at the faculty. To solve the problems described, a practical approach is needed to assist the academic advisor in providing more appropriate advices to the students. This paper proposed a machine learning based decision support system model which applied artificial neural network (ANN) as the decision support engine. This model facilitate academic advisor to make better decision when assigning students to their specialisation. This study has advocated the presumption that choosing the ideal course specialisation will increase students' learning interest and thus resulting better academic performance. The idea is based on the findings by Sangodiah (2014) who has proved that lack of interest is one of the reasons for students' attrition.

\subsection{RELATED WORK}

Using MongoDB as data storage platform and MapReduce paradigm for analytical process, Wassan (2015) has brought the insight where large volumes and variety of big data available in the educational institutions should be used effectively to generate meaningful information for better educational model. Literatures have showed that many endeavours focus on providing platforms or systems to support students for better learning experience in the academic environment. For instance, Engin et al. (2014) have developed a course advising and scholarship recommender system using Oracle Policy Automation (OPA) software. The system was developed based on rule-based expert system concept and function as a tool for the students to perform self-checking whether they are eligible to enrol to the courses they would like to take for following semester. Imran et al. (2015) have adopted association rule mining technique to develop a learning object recommender system for students' use to choose better learning strategy. El-Bishouty et al. (2014) have utilized genetic algorithm in the recommender systems developed for educators to extend courses planning strategy to accommodate more students with different learning styles. Numerous researches were conducted and systems were developed to provide academic advisory information to the students with different approaches such as fuzzy logic (Goodarzi \& Rafe, 2012), rule-based knowledge base with object oriented database (Ahmar, 2011) and service-based conventional system (Albalooshi \& Shatnawi, 2010). Furthermore, some researchers have demonstrated expert system development based on academic data for predicting students' performance and the result will then be used to plan for necessary intervention strategies (Altujjar et al., 2016; Badr et al., 2016; Goga et al., 2015; Lye et al., 2010; Thai-Nghe et al., 2010). Although the literatures have proved the possibility of computerized system integration to provide students' academic advising process, it is insufficient to assist students in choosing their specialisation. Not much of the work done focuses on providing the crucial functionality to facilitate the students in choosing their course specialisation, which will principally affect the rest of their 
academic path. Thus, it is the novelty of a research to build a platform to facilitate students to choose their course of specialisation with minimal intervention by an academic advisor.

\subsection{PROPOSED ACADEMIC ADVISORY MODEL}

The proposed academic advisory model is an extended module of $\mathrm{C} 1$, an automated online education management system by $\mathrm{Ng}$ et.al (2014). This model is functioned as a decision support engine to propose the specialisation that suits the students most by analysing their individual academic performance from different levels. It helps academicians to make more precise decisions when assigning specialisation to students. Artificial neural network technique is applied to model the decision support engine. Generally, a simple single layer ANN consists of four major components: input, weights, transfer function and output. The weight value of a neuron signifies the learning ability of a network. The transfer function determines if a neuron is activated and proceeds to obtain the output. The network learns by fine tuning the weight values of neurons through a series of activation process.

Figure 1 shows the proposed academic advisory model. The learning process of the model consists of three steps. The academicians first identify the inputs to the model. They are the assessment of subjects taken by the students in previous semesters. Each input value is then multiplied with the neuron's weight value. The net input value, $n$, is then obtained by Eq. 1 .

$$
n=w_{1} p_{1}+w_{2} p_{2}+w_{3} p_{3}+\cdots+w_{r} p_{r}+b
$$

where $p$ is individual element input, $w$ is weight.

The sum value, $n$, is the argument of the transfer function, $f$ and thus, the output, $a$, is obtained by the following equation (Eq. 2):

$$
a=f(n)=f\left(w_{1} p_{1}+w_{2} p_{2}+w_{3} p_{3}+\cdots+w_{r} p_{r}+b\right)
$$

If $a$ exceeds the threshold value, $\theta$, the activation process occurs. The neuron's weight value will then be adjusted if the actual output value differs from the desired output from the training data. The learning process continues until the network model reaches its optimum performance. 


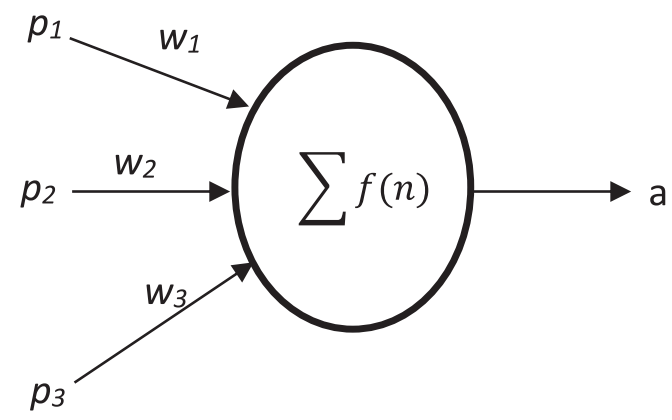

Figure 1. Schema of the proposed academic advisory model

\subsection{EXPERIMENTAL RESULTS}

School of Information Technology of SEGi University has been chosen as the platform to run the preliminary testing on the proposed academic advisory decision support engine. Three subject assessments of students in previous semesters have been taken as input data. They are web project coursework, advanced database coursework and examination marks. The third year students' records were sampled as training set for the model. $65 \%$ of the data was used to train the model. $25 \%$ and $10 \%$ of the data was used for validation and testing purpose respectively. A 10 layered neural network has been applied to construct the decision support engine. Figure 2 shows the prediction performance of the proposed model. The model has achieved $87.5 \%$ accuracy in predicting the suitable specialisation for students. The best validation performance was achieved at epoch 12 .

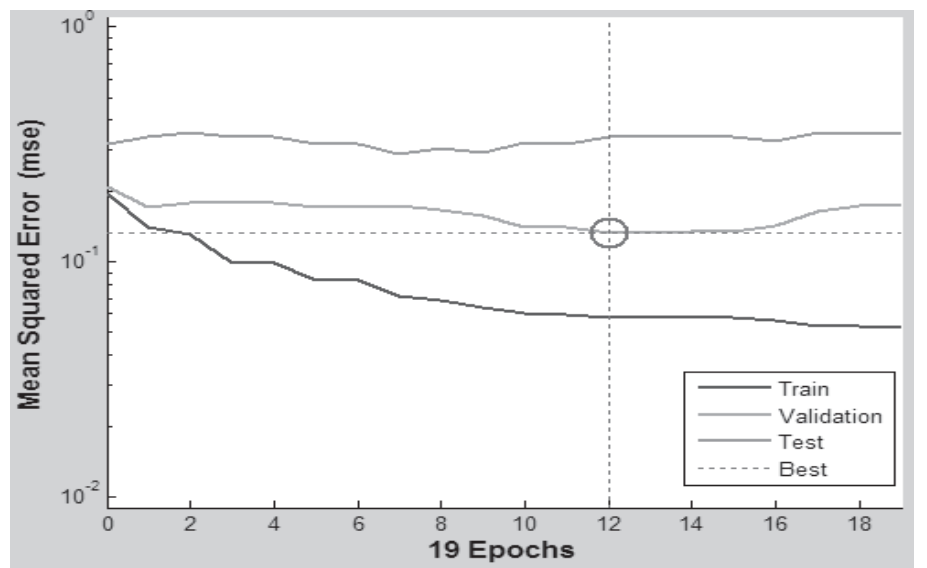

Figure 2. Accuracy of academic advisory decision support engine 
Figure 3 shows the confusion matrix for the academic advisory decision support engine. It can be observed that out of 25 records of SE (software engineering specialisation), 24 records are accurately predicted. The percentage is $96 \%$. On the other hand, out of 7 records of BSD (business software development specialisation), only 4 records are accurately predicted. The percentage is $57.1 \%$.
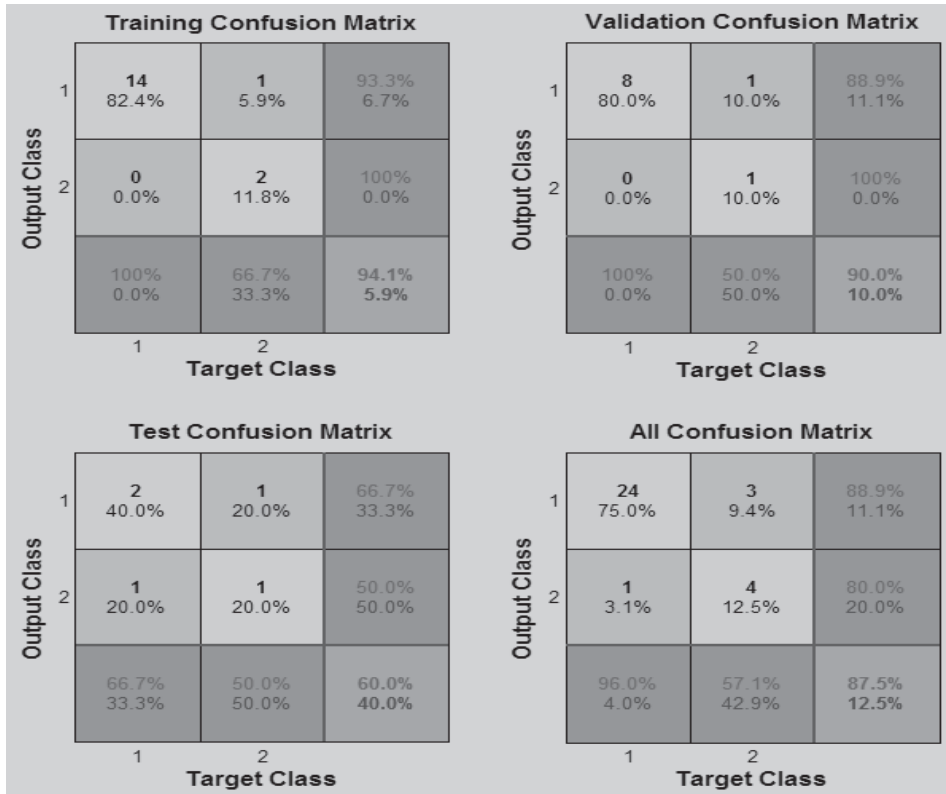

Figure 3. Confusion matrix for academic advisory decision support engine

\subsection{CONCLUSION}

The growth of higher education institution drop-out rate in recent years has become a global concern issue for all academicians and government. Extensive research has been conducted to investigate factors contributing to the high drop-out rate of university students. Part of the reason is due to the unsatisfactory learning experiences of students during their university studies. Choosing a suitable course specialisation is one of the prospects that ensures students' satisfaction in learning. The proposed machine learning based decision support model effectively simplifies the academic evaluation process in assigning students with appropriate specialization for their studies. The application of ANN on the advisory system has achieved promising results in classifying specialization for students based on their periodical academic performances. The future work will extend this method to university workforce management for effective teaching resources allocation. 
The authors are grateful to the School of Information Technology, SEGi University for providing the students' grade data to conduct the experiments in this study.

\subsection{REFERENCES}

- Abdykhalykova, Z. (2013). Extended Academic Advising in Kazakhstan: Improving the Success of First Year Students. In Cyprus International Conference on Educational Research (Vol. 89, pp. 357-362).

- Ahmar, M. Al. (2011). A Prototype Student Advising Expert System Supported with an Object-Oriented Database. International Journal of Advanced Computer Science and Applications, 100-105.

- Albalooshi, F., \& Shatnawi, S. (2010). HE-Advisor: A Multidisciplinary Web-Based Higher Education Advisory System. Global Journal of Computer Science and Technology, 10(7), 37-49.

- Alkan, N. (2014). Humor, Loneliness and Acceptance: Predictors of University Drop-out Intentions. In International Congress on Education (Vol. 152, pp. 1079-1086).

- Altujjar, Y., Altamimi, W., Al-Turaiki, I., \& Al-Razgan, M. (2016). Predicting Critical Courses Affecting Students Performance: A Case Study. In Symposium on Data Mining Applications (Vol. 82, pp. 65-71).

- Araque, F., Roldán, C., \& Salguero, A. (2009). Factors influencing university drop out rates. Computers and Education, 53(3), 563-574.

- Badr, G., Algobail, A., Almutairi, H., \& Almutery, M. (2016). Predicting Students' Performance in University Courses: A Case Study and Tool in KSU Mathematics Department. In Symposium on Data Mining Applications (Vol. 82, pp. 80-89).

- El-Bishouty, M. M., Chang, T.-W., Graf, S., Kinshuk, \& Chen, N.-S. (2014). Smart ecourse recommender based on learning styles. Journal of Computers in Education, 1(1), 99-111.

- Engin, G., Aksoyer, B., Avdagic, M., Bozanlı, D., Hanay, U., Maden, D., \& Ertek, G. (2014). Rule-based Expert Systems for Supporting University Students. In 2nd International Conference on Information Technology and Quantitative Management (Vol. 31, pp. 22-31).

- Goga, M., Kuyoro, S., \& Goga, N. (2015). A Recommender for Improving the Student Academic Performance. In The 6th International Conference Edu World 2014 "Education Facing Contemporary World Issues" (Vol. 180, pp. 1481-1488).

- Goodarzi, M. H., \& Rafe, V. (2012). Educational advisor system implemented by webbased fuzzy expert systems. Journal of Software Engineering and Applications, 5(7), 500-507.

- Imran, H., Belghis-Zadeh, M., Chang, T.-W., Kinshuk, \& Graf, S. (2015). PLORS: a personalized learning object recommender system. Vietnam Journal of Computer Science, $3(1), 3-13$.

- $\quad$ Lye, C. T., Ng, L. N., Hassan, M. D., Goh, W. W., Law, C. Y., \& Ismail, N. (2010). Predicting pre-university students' mathematics achievement. In International 
Conference on Mathematics Education Research (Vol. 8, pp. 299-306).

- Ng, S. C., Lee, T. S., Wong, C. K. \& Lee, F. Y. (2014). C1: an Automated Online Education Management System Based on an Object-Oriented Approach. Journal of Web Engineering, 13(1), 087 - 096.

- Sangodiah, A. (2014). Holistic Prediction of Student Attrition in Higher Learning Institutions in Malaysia Using Support Vector Machine Model. International Journal of Research Studies in Computer Science and Engineering, 1(1), 29-35.

- Sangodiah, A., Beleya, P., Muniandy, M., Heng, L. E., \& Ramendran Spr, C. (2015). Minimizing student attrition in higher learning institutions in Malaysia using support vector machine. Journal of Theoretical and Applied Information Technology, 71(3), 377385.

- Thai-Nghe, N., Drumond, L., Krohn-Grimberghe, A., \& Schmidt-Thieme, L. (2010). Recommender system for predicting student performance. In 1stWorkshop on Recommender Systems for Technology Enhanced Learning (Vol. 1, pp. 2811-2819).

- Wassan, J. T. (2015). Discovering Big Data Modelling for Educational World. In International Educational Technology Conference (Vol. 176, pp. 642-649). 